\title{
Influence of Mg content on defect-related luminescence of undoped and doped wurtzite MgZnO ceramics
}

\author{
I.V. Markevich, T.R. Stara, V.O. Bondarenko \\ V. Lashkaryov Institute of Semiconductor Physics, NAS of Ukraine, \\ 41, prospect Nauky, 03028 Kyiv, Ukraine; \\ Phone: +38(044)525-7234; e-mail: stara_t@ukr.net
}

\begin{abstract}
Undoped as well as Li-, Ag-, $\mathrm{Cu}$ - and $\mathrm{Zn}$-doped $\mathrm{Mg}_{\mathrm{x}} \mathrm{Zn}_{1-\mathrm{x}} \mathrm{O}$ ceramics with $x=$ $0-0.20$ were sintered at $1000^{\circ} \mathrm{C}$. Defect-related photoluminescence (PL) and PL excitation spectra were measured at room temperature in 400-800 nm and 250-400 nm spectral ranges, accordingly. Two types of PL bands were observed: i) the bands, spectral positions of which were not influenced by the $\mathrm{Mg}$ content (Cu-related as well as selfactivated orange and red ones); ii) the bands, spectral positions of which exhibited some blueshift with increasing $\mathrm{Mg}$ content (Li- and Ag-related and self-activated green ones). It has been shown that used doping gives the possibility to obtain the phosphor with intense visible emission within the blue-yellow spectral range.
\end{abstract}

Keywords: MgZnO alloy, doping, photoluminescence.

Manuscript received 25.03.15; revised version received 30.07.15; accepted for publication 03.09.15; published online 30.09.15.

\section{Introduction}

In recent years, the MgZnO ternary system attracts much attention as a promising material for UV light emitters. Alloying with $\mathrm{MgO}$ results in essential broadening the $\mathrm{ZnO}$ bandgap and gives the possibility to shift nearband-edge emission into deep ultraviolet, which calls forth the extensive investigation of UV emission in these solid solutions. On the other hand, MgZnO composition can be considered as a potential candidate for fabricating white-light phosphors. In fact, zinc oxide is known to demonstrate visible emission in a comparatively broad spectral range [1, 2]. One can expect that alloying with $\mathrm{MgO}$ will affect $\mathrm{ZnO}$ defect-related emission and will enable to modify its intensity and spectrum. Up to now, however, the reported data on the influence of $\mathrm{Mg}$ content on defect-related emission in MgZnO alloys are rather scarce and controversial. With increasing the $\mathrm{Mg}$ content, both the enhancement [3-5] and weakening $[6,7]$ of the visible emission intensity were observed. In $[3-6,8]$, the shift of defect-related emission band toward the short wavelength side as a result of alloying $\mathrm{ZnO}$ with MgO was found, whereas in $[9,10]$ any change of emission band shape or peak position was not observed. In [11], it was shown that self-activated defect-related emission in sol-gel MgZnO phosphors can be shifted from the orange to green-blue spectral region by changing the annealing temperature and gas ambient. The data on impurity-related emission in MgZnO alloys are, in fact, absent in the available literature.

It was earlier shown that, in MgZnO ceramics, a blueshift of self-activated green emission took place with increasing $\mathrm{Mg}$ content [12]. In the present paper, this effect has been considered in more detail, and investigation of photoluminescence (PL) in MgZnO ceramics undoped as well as doped with lithium, silver and copper has been performed.

\section{Experimental procedure}

The samples were formed of the mixture of $\mathrm{ZnO}$ (99.99\% purity) and MgO (99.99\% purity) powders with 
distillate water as well as $\mathrm{LiNO}_{3}, \mathrm{AgNO}_{3}$ or $\mathrm{CuCl}_{2}$ aqueous solutions, the concentration of impurity being about $10^{18} \mathrm{~cm}^{-3}$. The Mg content $x$ was changed from 0 up to 0.20 , which was found to be the solubility limit of $\mathrm{Mg}$ in hexagonal-structure $\mathrm{Mg}_{\mathrm{x}} \mathrm{Zn}_{1-\mathrm{x}} \mathrm{O}$ ceramics [13]. After drying at room temperature, the samples were sintered in air at $1050{ }^{\circ} \mathrm{C}$ for 3 hours and cooled with the furnace. A number of undoped samples were also sintered in $\mathrm{Zn}$ vapor. In this case, the samples were located in a closed crucible with metallic zinc scraps and annealed in $\mathrm{N}_{2}$ flow. In all cases, firm and dense hexagonal phase ceramics were obtained (X-ray diffraction patterns were shown in [13]). Prepared samples were cut transversally and defect-related PL spectra in $400-800 \mathrm{~nm}$ range as well as PL excitation (PLE) spectra in 250-400 nm range were measured from cleft surface at room temperature. Xe-lamp light passing through grating monochromator was used as exciting source. The wavelength of $320 \mathrm{~nm}$ that produced bandto-band transitions in all the investigated samples was used for PL excitation. PLE spectra were measured at the fixed wavelength corresponding to the maximum of PL band under investigation. The broadening of $\mathrm{ZnO}$ bandgap due to adding $\mathrm{MgO}$ was monitored by the shift of PLE peak, the position of which was known to coincide with that of the free exciton emission band [13]

\section{Results and discussion}

PLE spectra of undoped ceramics with different $x$ values are shown in Fig. 1. One can see that increasing the $\mathrm{Mg}$ content from $x=0$ up to 0.20 results in the shift of PLE maximum from $380 \mathrm{~nm}(3.26 \mathrm{eV})$ to $340 \mathrm{~nm}(3.64 \mathrm{eV})$. The influence of doping on PLE spectra was not observed: in all the samples, independently of used impurity, PLE peak positions were the same for the same $x$ values.

\subsection{Photoluminescence of doped $\mathrm{MgZnO}$ ceramics}

The ceramics sintered in Zn vapor demonstrated extremely intense blue-green PL band, the peak position of which was shifted toward the shorter wavelength side from 515 down to $485 \mathrm{~nm}$ with the increasing $x$ value (Fig. 2).

Doping with $\mathrm{Li}$ and $\mathrm{Ag}$ caused appearance of orange bands peaking at 600 and $580 \mathrm{~nm}$, accordingly, at $x=0$. Increasing $x$ resulted in the shift of these bands toward shorter wavelengths (Figs. 3 and 4).

The samples doped with $\mathrm{Cu}$ demonstrated the green PL band peaking at $540 \mathrm{~nm}$, which did not change its position with increasing $x$ (Fig. 5).

\subsection{Photoluminescence of undoped $\mathrm{MgZnO}$ ceramics}

Defect-related emission in intentionally undoped $\mathrm{ZnO}$ is known to demonstrate itself as a broad band consisting of green, orange and red ones, relative intensities of these bands depending on preparation conditions [1,2]. Green emission, in its turn, includes self-activated

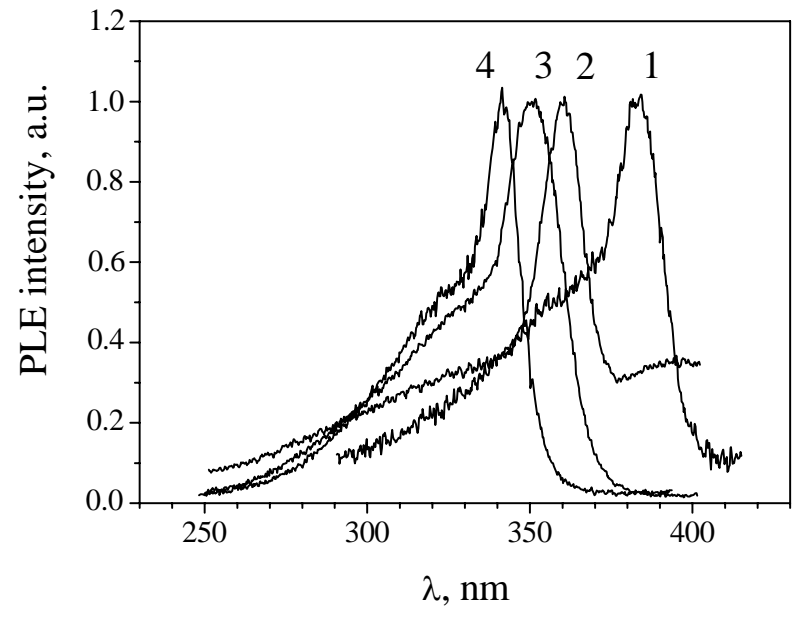

Fig. 1. PLE spectra of undoped $\mathrm{Mg}_{\mathrm{x}} \mathrm{Zn}_{1-\mathrm{x}} \mathrm{O}$ ceramics with different $x$ : 0 (1), 0.10 (2), 0.20 (3).

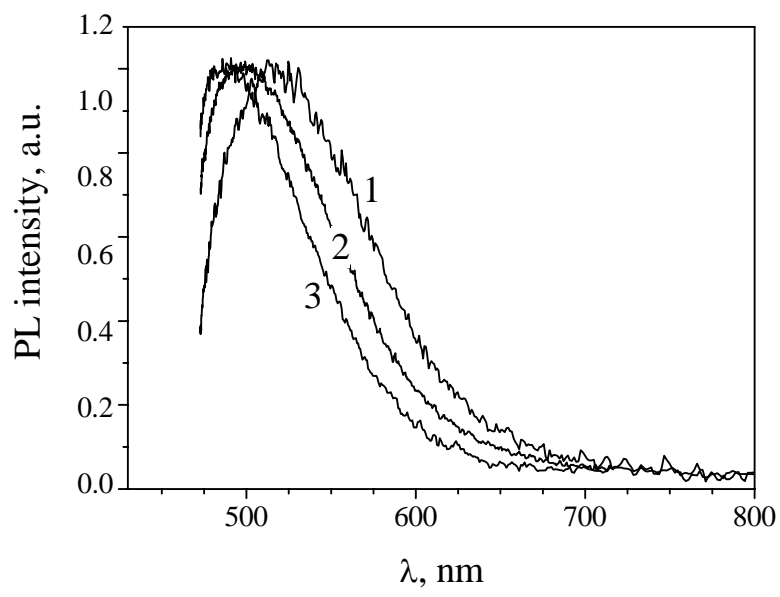

Fig. 2. $\mathrm{PL}$ spectra of sintered in $\mathrm{Zn}$ vapor $\mathrm{Mg}_{\mathrm{x}} \mathrm{Zn}_{1-\mathrm{x}} \mathrm{O}$ ceramics different $x$ : 0 (1), 0.10 (2), 0.20 (3).

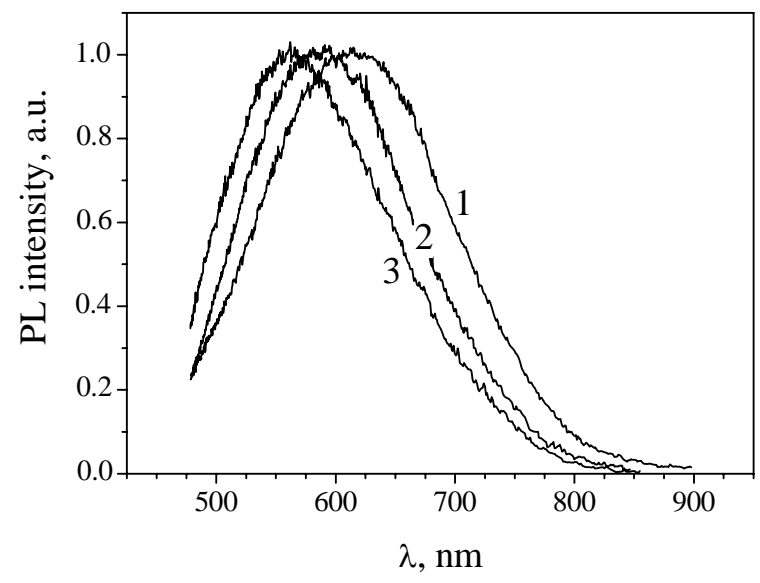

Fig. 3. $\mathrm{PL}$ spectra of Li-doped $\mathrm{Mg}_{\mathrm{x}} \mathrm{Zn}_{1-\mathrm{x}} \mathrm{O}$ ceramics with different $x$ : 0 (1), 0.10 (2), 0.20 (3). 


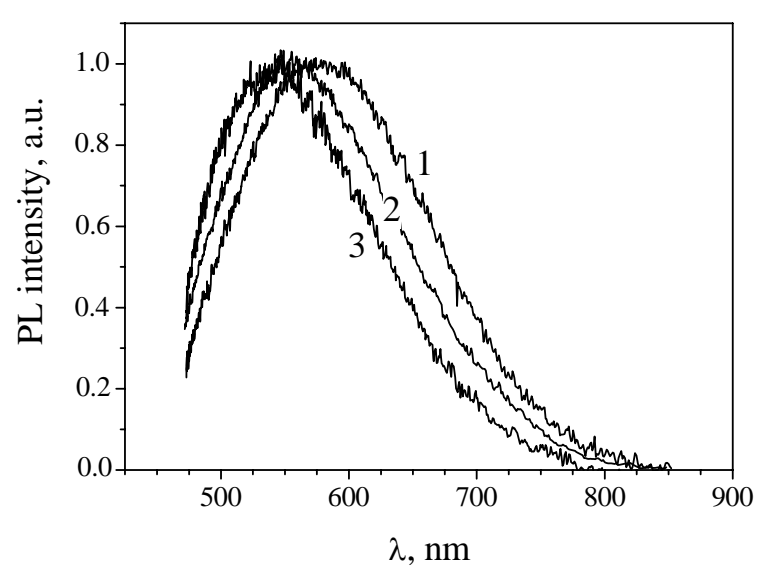

Fig. 4. PL spectra of Ag-doped $\mathrm{Mg}_{\mathrm{x}} \mathrm{Zn}_{1-\mathrm{x}} \mathrm{O}$ ceramics with different $x$ : 0 (1), 0.10 (2), 0.20 (3).

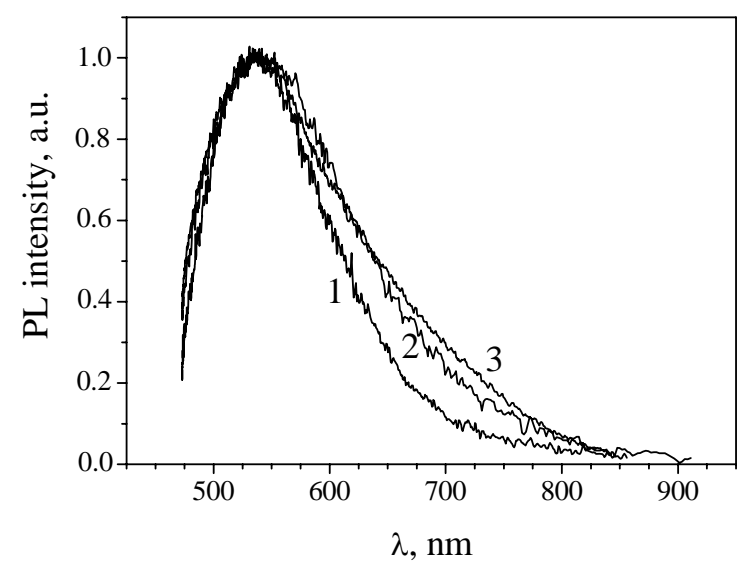

Fig. 5. PL spectra of $\mathrm{Cu}$-doped $\mathrm{Mg}_{\mathrm{x}} \mathrm{Zn}_{1-\mathrm{x}} \mathrm{O}$ ceramics with different $x$ : 0 (1), 0.10 (2), 0.20 (3).

and Cu-related bands [1, 2, 14]. Red emission is often concealed in the tail of the orange one but sometimes displays itself as a distinct band at about $700 \mathrm{~nm}$ $[1,15,16]$.

PL spectra of undoped ZnMgO ceramics are shown in Figs. 6a-6c. The intensity of defect-related emission in undoped samples was noticeably weaker than that in the doped ones. It was also found that PL intensity remained, in fact, the same at $x=0.10$ but increased markedly at $x=20$ with respect to the samples with $x=0$. With increasing the Mg content, PL band showed at first red shift (Fig. 6b) and then blue shift (Fig. 6c). To clarify the origin of this behavior, Gaussian deconvolution of the obtained PL spectra was performed. Before this procedure, the samples with different $x$ values exhibiting distinct red PL band were chosen and their PL spectra were compared. It was found that the peak of self-activated red band was located at $720 \mathrm{~nm}$, and its position was independent of the Mg content (Fig. 7).

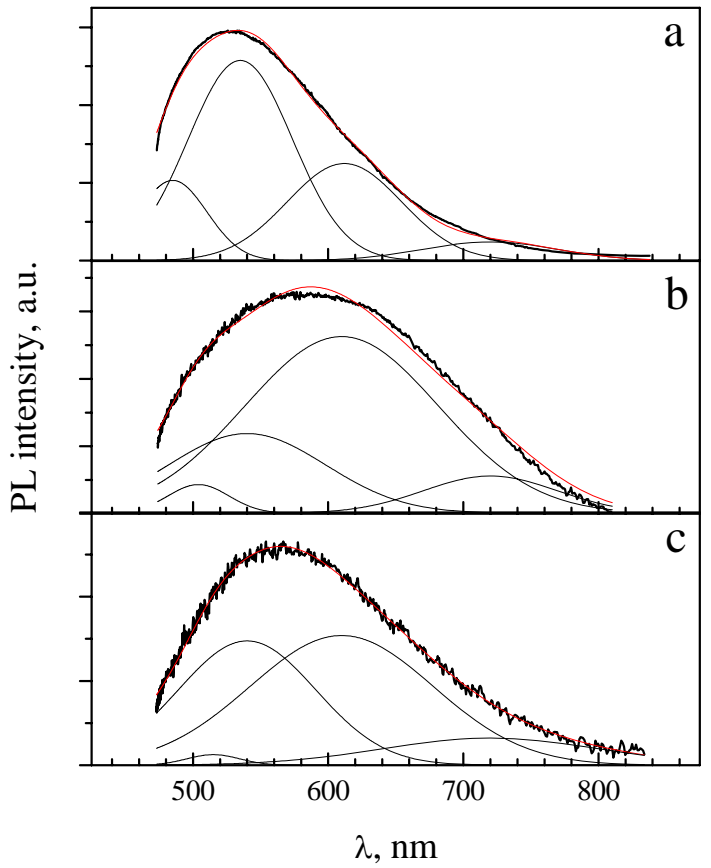

Fig. 6. $\mathrm{PL}$ spectra of undoped $\mathrm{Mg}_{\mathrm{x}} \mathrm{Zn}_{1-\mathrm{x}} \mathrm{O}$ ceramics with different $x$ : 0 (1), 0.10 (2), 0.20 (3).

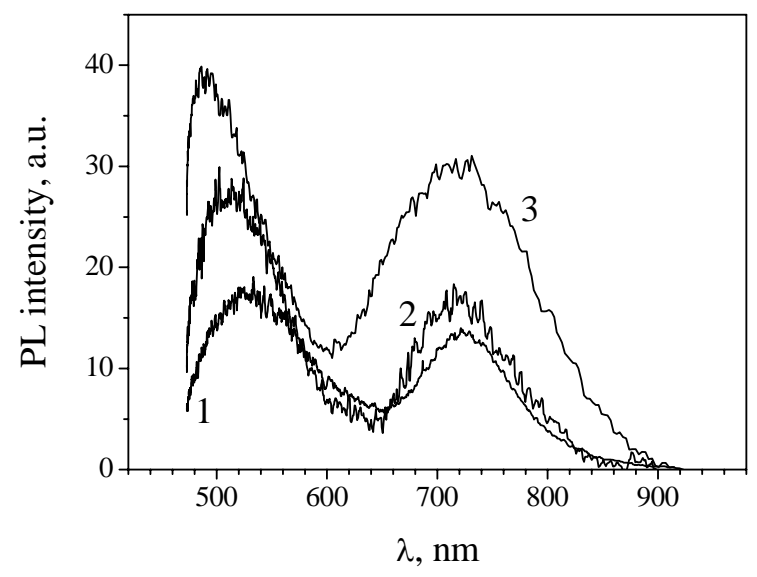

Fig. 7. PL spectra of undoped $\mathrm{Mg}_{\mathrm{x}} \mathrm{Zn}_{1-\mathrm{x}} \mathrm{O}$ ceramics with different $x$ exhibiting distinct red band: 0 (1), 0.10 (2), 0.20 (3).

Gaussian deconvolution of PL spectra obtained for undoped samples was performed using the determined above peak positions of self-activated and Cu-related green bands as well as that of red one (Fig. 6). As a result, the orange emission band with the same peak position at $610 \mathrm{~nm}$ was separated for all the used $x$ values. From the data displayed in Fig. 6, one can conclude that, with increasing the Mg content, at first formation of "orange"emission centers and then appearance of "green" ones takes place. The enhancement of orange emission due to $\mathrm{Mg}$ introduction was also observed for $\mathrm{Mg}_{\mathrm{x}} \mathrm{Zn}_{1-\mathrm{x}} \mathrm{O}$ ceramics with $x<0.15$ in [17]. 
Thus, there are two types of emission centers in MgZnO alloys with different behavior of corresponding energy levels: i) the centers, which PL band peak position is not influenced by the $\mathrm{Mg}$ content (Cu-related as well as self-activated orange and red centers); ii) the centers, which PL band position demonstrates the blue shift with increasing the Mg content (Li- and Ag-related as well as self-activated blue-green centers). For the first-type centers, two possibilities should be considered: i) center energy level is pinned to the involved allowed band from which carrier recombination on the center occurs; ii) this emission is caused by the intra-defect transition, excited and ground states of the center being weakly coupled to the band properties of the host lattice. The latter has been stated for $\mathrm{Cu}_{\mathrm{Zn}}$ acceptor in $\mathrm{ZnO}$ $[1,2]$. For orange and red self-activated centers, the former possibility seems to be more probable. The related emission bands were shown to appear due to stoichiometric oxygen excess, and electron transitions from $c$-band or shallow donor to deep acceptor are supposed to be responsible for these bands [1,2]. The second-type centers show the shift of their energy level position with respect to the involved allowed band under bandgap broadening. This shift is about $0.2 \mathrm{eV}$ at $x=0.20$ for all the second-type centers, which is twice as little as that of free exciton (Fig. 1) and, hence, of bandgap broadening $(0.4 \mathrm{eV})$. One can think, therefore, that energy levels of these centers shift equally with respect to both $c$ - and $v$-bands. It should be noted, however, that electron-hole transitions responsible for specific emission bands in $\mathrm{ZnO}$ still remain highly disputable throughout the literature, and further investigations in this field are required.

The obtained results show that defect-related emission in undoped MgZnO ceramics is rather weak. At the same time, phosphors with bright blue and greenyellow emissions can be prepared by doping this material with $\mathrm{Zn}, \mathrm{Li}$ and Ag. To obtain white-light phosphor based on MgZnO alloy, the impurity, which will produce intense emission in orange-red spectral region, should be found.

\section{Conclusion}

To reveal the influence of alloying $\mathrm{ZnO}$ with $\mathrm{MgO}$ on impurity-related and self-activated emissions of material, PL spectra of doped with Li-, Ag-, $\mathrm{Cu}-$ and $\mathrm{Zn}$ as well as of undoped $\mathrm{Mg}_{\mathrm{x}} \mathrm{Zn}_{1-\mathrm{x}} \mathrm{O}$ ceramics with $x=0-0.20$ were investigated. It was found that the doped samples demonstrated more intense PL than the undoped ones and that used doping enabled to prepare $\mathrm{MgZnO}$ phosphors with bright emission in the blue-yellow spectral range. It was shown that spectral positions of some PL bands, namely, of green Cu-related as well as the self-activated orange and red ones, were not influenced by the Mg content. At the same time, Li-, Agand Zn-related PL bands showed some blue shift with increasing Mg content, this blue shift being the same for all the mentioned bands and reaches about $0.20 \mathrm{eV}$ at $x=0.20$. Based on these facts, it should be stated that there are two types of emission centers, which different reaction to $\mathrm{ZnO}$ bandgap broadening by alloying with $\mathrm{MgO}$ indicates their different interaction with the host lattice.

\section{Acknowledgments}

This research has been financially supported by National Academy of Sciences of Ukraine (project III-4-11).

\section{References}

1. I. Kuzmina, V. Nikitenko, Zinc Oxide. Production and Optical Properties. Nauka, Moscow, 1984 (in Russian).

2. U. Ozgur, Ya.I. Alivov, C. Liu, A. Teke, M.A. Reshchikov, S. Dogan, V. Avrutin, S. J.Cho, H. Morkos, A comprehensive review of $\mathrm{ZnO}$ materials and devices // Appl. Phys. Rev., J. Appl. Phys. 98, p. 041301 (1-102) (2005).

3. J. Zhang, F. Pan, W. Hao, T. Wang, Effect of MgO doping on the luminescent properties of $\mathrm{ZnO} / /$ Mater. Sci. Eng. B, 129, p. 93-95 (2006).

4. P. Kumar, J.P. Singh, Y. Kumar, A. Gaur, H.K. Malik, K. Asokan, Investigation of phase segregation in $\mathrm{Zn}_{1-\mathrm{x}} \mathrm{Mg}_{\mathrm{x}} \mathrm{O}$ systems // Current. Appl. Phys. 12, p. 1166-1172 (2012).

5. S. Sharma, R. Vyas, N. Sharma, V. Singh, A. Singh, V. Kataria, B.K. Gupta, Y.K. Vijay, Highly efficient green light harvesting from $\mathrm{Mg}$ doped ZnO nanoparticles: structural and optical studies // J. Alloys Comp. 552, p. 208-212 (2013).

6. J.P. Singh, A. Vij, D. Kumar, P.K. Khanna, M. Kumar, S. Gautam, K.H. Chae, Investigation of phase segregation in sol-gel derived ZnMgO thin films // Semicond. Sci. Technol. 28, p. 025004 (1-8) (2013).

7. A.K. Sharma, J. Narayan, J.F. Muth, C.W. Teng, C. Jin, A. Kvit, R.M. Kolbas, O.W. Holland, Optical and structural properties of epitaxial $\mathrm{Mg}_{\mathrm{x}} \mathrm{Zn}_{1-\mathrm{x}} \mathrm{O}$ alloys // Appl. Phys. Lett. 75, p. $3327-$ 3329 (1999).

8. Th.A. Wassner, B. Laumer, S. Maier, A. Laufer, B.K. Meyer, M. Stutzmann, M. Eickhoff, Optical properties and structural characteristics of ZnMgO grown by plasma assisted molecular beam epitaxy // J. Appl. Phys. 105, p. 023505 (1-6) (2009).

9. H. Li, Y.Zhang, X. Pan, T. Wang, E. Xie, The effect of thermal annealing on properties of $\mathrm{Mg}_{\mathrm{x}} \mathrm{Zn}_{1-\mathrm{x}} \mathrm{O}$ films by sputtering // J. Alloys Comp. 472, p. 208-210 (2009).

10. Q. Shi, J. Zhang, D. Zhang, Ch. Wang, B. Yang, B. Zhang, W. Wang, Red luminescent and structural properties of Mg-doped $\mathrm{ZnO}$ phosphors prepared by sol-gel method // Mater. Sci. Eng. B, 177, p. 689-693 (2012). 
11. Q. Shi, Zh. Wang, Yu. Liu, B. Yang, G. Wang, W. Wang, J. Zhang, Single-phased emissiontunable Mg-doped $\mathrm{ZnO}$ phosphors for white LEDs // J. Alloys Comp. 553, p. 172-176 (2013).

12. I.V. Markevich, T.R. Stara, A.S. Romanyuk, O.F. Kolomys, V.V. Strelchuk, Influence of annealing in $\mathrm{Zn}$ vapor on luminescence of MgZnO ceramics // physica status solidi (c), 11, p. 14851487 (2014).

13. I.V. Markevich, T.R. Stara, A.V. Kuchuk, Yu.O. Polishchuk, V.P. Kladko, Formation of MgZnO alloy under thermodynamic conditions // Physica $B$, 453, p. 123-126 (2014).
14. I.V. Markevich, T.V. Stara, V.O. Bondarenko, About self-activated orange emission band in $\mathrm{ZnO}$ // Semiconductor Physics, Quantum Electronics and Optoelectronics, 18(2), p. 134-137 (2015).

15. R.B. Lauer, The IR photoluminescence emission band in ZnO // J. Phys. Chem. Sol. 34, p. 249-253 (1973).

16. Yu.M. Gerbshtein, Ya.M. Zelikin, About red luminescence band in zinc oxide // Opt. Spectrosc. 28, p. 521-523 (1970).

17. J. Zhang, Zh. Zhang, T. Wang, A new luminescent phenomenon of $\mathrm{ZnO}$ due to the precipitate trapping effect of $\mathrm{MgO} / /$ Chem. Mater. 16, p. 768-770 (2004). 